Viso - Cadernos de estética aplicada Revista eletrônica de estética

ISSN 1981-4062

$N^{\circ} 10$, jan-dez/2011

http://www.revistaviso.com.br/

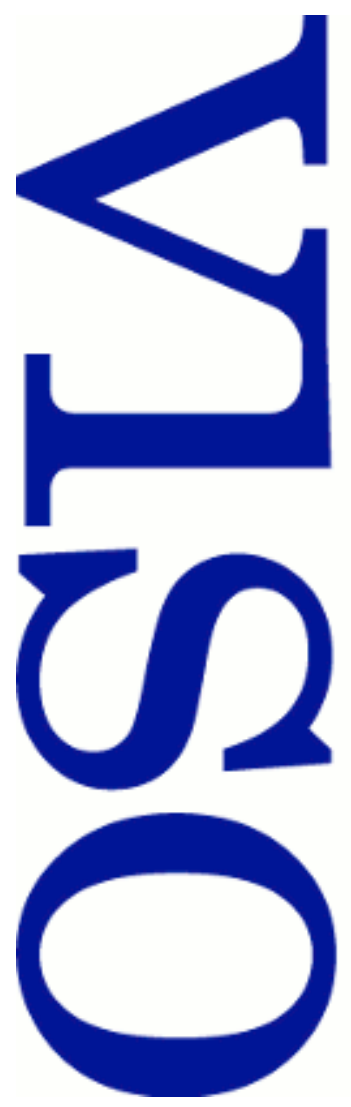

\title{
A aura na era do seu anunciado declínio: Em torno de Cópia fiel de Abbas Kiarostami João Pedro Cachopo
}

Universidade Nova de Lisboa 


\section{RESUMO}

A aura na era do seu anunciado declínio: Em torno de Cópia fiel, de Abbas Kiarostami

As linhas que se seguem debruçam-se sobre um filme recente do realizador iraniano Abbas Kiarostami, Cópia fiel (2010), e nele mergulham para reflectir, de uma perspectiva contemporânea, sobre as noções de cópia, de ficção, de simulacro e, em certa medida surpreendentemente, de aura. Dão ensejo a estas reflexões o "tema" e a "estrutura" do filme: o facto de nele um historiador de arte discorrer sobre o valor da cópia em arte (e na vida), e a circunstância de a certo ponto, sensivelmente a meio do filme, os seus dois protagonistas (o historiador e uma coleccionadora de arte com quem trava conhecimento em Itália) parecerem simular um relação amorosa. A certa altura, as certezas do espectador vacilam: James e Elle conheceram-se há pouco (como sugere a primeira parte do filme), ou mantêm uma relação desde há muito (como quem visse apenas a segunda parte do filme julgaria). A resposta parece indecidível. Uma ficção desdobra-se no interior de outra; porém nenhuma tem primazia; a cópia (a fiç̧ão fictícia) torna-se independente do original (a pretensa ficção verdadeira); sobrevém um simulacro. Mas qual é o poder deste? Até que ponto a ficção poderá transformar a vida, resgatá-la à banalidade, transfigurá-la? É a partir de perguntas como estas que arriscaremos a hipótese paradoxal de uma cópia provida de aura. Com esta hipótese (com a qual se subverte a associação tradicional entre aura e original), é o poder transformador da arte (em relação com a vida) que permanece em jogo, para lá e independentemente da falência da distinção entre cópia e original.

Palavras-chave: Kiarostami - cópia - simulacro - aura 


\section{ABSTRACT}

The Aura in the Era of its Proclaimed Decline: Some Notes on Certified Copy, by Abbas Kiarostami

The following text focuses on a recent film of the Iranian director Abbas Kiarostami, Certified Copy (2010), and delves into it in order to reflect (with an eye to the present) upon the notions of copy, fiction, simulacrum, and, surprisingly enough, aura. One comes up against these issues due to the "theme" and the "structure" of the movie: considering that it features an art historian discussing the value of copy in art (as in life), and that suddenly, in the middle point of the film, both protagonists (the art historian, and a woman with deep interest in art, with whom he gets acquainted in Italy) seem to act out a relationship. The spectator's certainties fade out: have James and Elle recently met each other (as the first part of the film suggests), or do they maintain a relationship long since (as whoever watches the movie, having missed the first part, would guess)? The answer turns out to be undecidable. A fiction unfolds within another fiction; however, none of them have primacy; the copy (the fictitious fiction) becomes independent from the original (the alleged true fiction); a simulacrum comes to the floor. How powerful is the latter? To what extent might a fiction transform life, rescue it from banality, or transfigure it? These questions encourage us to hazard the paradoxical hypothesis of there being a copy with aura. By this hypothesis (as we subvert the traditional association between aura and originality), it is the very transforming power of art (with regard to life) that remains at stake, beyond and independently of the bankruptcy of the distinction between original and copy.

Keywords: Kiarostami - copy - simulacrum - aura 
CACHOPO, J. P. "A aura na era do seu anunciado declínio: Em torno de Cópia fiel, de Abbas Kiarostami". In: Viso: Cadernos de estética aplicada, v. V, n. 10 (2011), pp. 44-55.

DOI: 10.22409/1981-4062/v10i/110

Aprovado: 08.02.2012. Publicado: 19.04.2012.

(C) 2012 João Pedro Cachopo. Esse documento é distribuído nos termos da licença Creative Commons Atribuição-NãoComercial 4.0 Internacional (CC-BY-NC), que permite, exceto para fins comerciais, copiar e redistribuir o material em qualquer formato ou meio, bem como remixá-lo, transformá-lo ou criar a partir dele, desde que seja dado o devido crédito e indicada a licença sob a qual ele foi originalmente publicado.

Licença: http://creativecommons.org/licenses/by-nc/4.0/deed.pt_BR

Accepted: 08.02.2012. Published: 19.04.2012.

(C) 2012 João Pedro Cachopo. This document is distributed under the terms of a Creative Commons Attribution-NonCommercial 4.0 International license (CC-BY-NC) which allows, except for commercial purposes, to copy and redistribute the material in any medium or format and to remix, transform, and build upon the material, provided the original work is properly cited and states its license.

License: http://creativecommons.org/licenses/by-nc/4.0/ 
A reflexão que se segue ${ }^{1}$ - sobre temas relativos à noção de "imagem", à diferença entre "original" e "cópia", ao conceito de "aura" e, quase por arrasto, à relação da arte com a vida nos dias de hoje - debruça-se sobre Cópia fiel (2010), o mais recente filme do realizador iraniano Abbas Kiarostami. Nesta medida, e sem saber quão familiarizado está o leitor com a obra deste realizador e, em particular, com este seu trabalho, começo por fazer uma brevíssima síntese do enredo do filme em apreço.

A acção de Cópia fiel - uma ficção - tem lugar numa pequena vila do sul de Itália (na Toscânia), onde acaba de ser publicada a tradução de um livro de um escritor inglês vivo - intitulado, precisamente, Cópia fiel -, o qual versa sobre o estatuto histórico (passado e presente) da obra de arte e aborda problemáticas afins às suas transmissão e reprodução. O próprio autor deste livro, James Miller, está presente no lançamento do mesmo - a que assistimos no início do filme - e acaba por travar conhecimento com uma leitora entusiasmada do seu trabalho, Elle (personagem interpretada por Juliette Binoche), que, por sua vez, gere uma loja de antiguidades na mesma localidade. $O$ facto de partilharem vários interesses - sobre arte e história, nomeadamente - dá ensejo a um pequeno passeio de carro pela região, durante o qual a cumplicidade entre ambos crescerá de um modo extremamente rápido e a vários títulos surpreendente.

É ao longo deste passeio que se dá o que julgo ser o momento decisivo de Cópia fiel - o seu "momento pregnante", para falar como Lessing e Barthes -, a saber, a sequência, sensivelmente a meio do filme, em que a dona de um pequeno café da região os confunde com um casal, momento a partir do qual ambos passam a comportar-se efectivamente enquanto tal, já não como duas pessoas que acabaram de se conhecer, mas enquanto marido e mulher, casados há sensivelmente quinze anos. Até ao final do filme, tudo se passará como se fossem, realmente, um casal.

Ora, o advérbio "realmente" é uma palavra suspeita em cinema e poderíamos inclusive acrescentar, neste contexto, que a problematização da fronteira entre realidade e ficção constitui uma das obsessões férteis da obra de Kiarostami (pense-se paradigmaticamente num filme como Close-up, um dos mais notáveis da sua produção). No caso de Cópia fiel, a ficção desdobra-se no interior de si própria, duplicando-se, e dissemina-se por meio dessa duplicação. Pois, no próprio contexto de uma ficção, os personagens parecem simular uma outra ficção alternativa; tanto quer dizer, portanto, que eles, por assim dizer, simulam simular uma ficção, fazendo de conta que são um casal...

Mas - cabe perguntar - que sentido faz distinguir uma espécie de sub-ficção no interior da ficção principal, estabelecendo uma hierarquia entre ambas, como se tivéssemos, durante a primeira parte do filme, a "ficção-real" (em que tudo se passa como se assistíssemos ao encontro de uma mulher e de um homem até então desconhecidos um do outro) e, na segunda parte, a "fiç̧ão-fictícia" (em que tudo se passa como se há muito se conhecessem, como se fossem um casal e há muito partilhassem um quotidiano nem 
sempre isento de conflitos, ressentimentos, desilusões)? Por que razão seria a primeira ficção mais real do que a segunda? Qual seria o critério que permitiria estabelecer uma tal distinção? À partida, quase instintivamente, tenderíamos a procurar um tal critério no princípio da verosimilhança. No entanto, este revela-se falível, pois alguém que, por alguma razão, entrasse no cinema a meio do filme, e o visse daí até ao fim, em nenhum momento suspeitaria de que James e Elle não são um casal. De facto, isolada da primeira parte, a segunda parte do filme não é menos verosímil do que a antecedente; em nenhum momento, pois, a segunda parte é em si mesma contraditória. Só conjugadas, as duas partes revelam a sua compossibilidade paradoxal; algo que nos faz pensar na obra de Escher..

Pensemos pois numa dessas imagens da sua autoria em que quatro lances de escadas simultaneamente ascendentes e descendentes, ligados entre si perpendicularmente, se sucedem ad infinitum, pois o quarto lance desemboca, paradoxalmente, no primeiro. Em Cópia fiel, é como se o paradoxo de uma tal imagem se desdobrasse no tempo. Pois, assim como quem isolasse visualmente (numa imagem de Escher) os primeiros dois lances de escadas dos dois seguintes não se aperceberia do paradoxo e não poderia dizer que uma das metades é mais ou menos congruente do que a outra, assim também, em Cópia fiel, quem analisasse separadamente cada uma das partes do filme, ao reconhecer que ambas são igualmente verosímeis, não teria como identificar a ficção original e, por conseguinte, não teria como decidir qual é a "ficção-real" por oposição à "ficção-fictícia", menos real, menos autêntica, cópia de cópia, mero simulacro.

Diferentemente do que sucede em Close-up, por exemplo - em que o real e a ficção se misturam, em virtude da imbricação entre os registos "documental" e "ficcional" -, em Cópia fiel, a realidade e a ficção confundem-se no meio da própria ficção, ao ponto de já não ser possível distinguir o original (a realidade dentro da ficção) da cópia (a ficção dentro da ficção). É nesta indiscernibilidade - entre original e cópia, entre realidade e ficção - que reside o carácter enigmático desta obra de Kiarostami. Não obstante - como sempre, aliás, quando está em jogo o "enigmático" em arte -, a questão não é a de chegar a saber a resposta - no caso, a poder identificar o original - mas a de se demorar na dúvida e, sobretudo, a de tirar dessa interrogação demorada as consequências mais fecundas.

Não sendo já possível distinguir a cópia do original - nem legítimo separar categoricamente realidade e ficção -, é pois da emancipação da cópia ou do fim da hierarquia entre a cópia e o original que se trata; temáticas, como sabemos, de cunho benjaminiano, que, no célebre ensaio sobre "A obra de arte na era da sua reprodutibilidade técnica", se relacionam com a questão do "declínio da aura". De forma subtil mas inegável, todos estes tópicos apresentam afinidades com o tema do livro que James escrevera sobre arte - o que, de resto, torna patente a extraordinária imbricação entre forma e conteúdo neste filme. 
Na cena em que conversam no café, James confessa a Elle que teve a ideia do livro ao observar de longe, há cerca de cinco anos, em Florença - mais especificamente, na Piazza della Signoria, onde se encontram numerosas reproduções de esculturas renascentistas -, a conversa entre uma mãe e um filho pequeno (que entretanto compreendemos serem, aparentemente por coincidência, a própria Elle e o seu filho). James, apesar de à distância a que se encontrava não conseguir ouvir o que diziam, mas podendo observar os seus gestos, imaginou o que poderia ter sido a conversa entre ambos: segundo ele, a mãe, verificando o espanto da criança diante de uma das esculturas, deixou-a acreditar que estavam perante o original, ou seja, perante uma figura humana esculpida num bloco de pedra que, tendo atravessado séculos, fora produzida há muito pelas próprias mãos do artista. A ideia do livro teria provindo deste episódio, da experiência de uma criança que se espanta perante uma cópia que acredita ser o original.

A cópia, tal é a tese principal do livro de James, tem um valor intrínseco, sendo que é possível, segundo o próprio James, levar esta tese ao extremo, propondo "um paralelo entre a reprodução na arte e a reprodução na raça humana". Apesar de James, na conferência em que apresenta o seu livro, resumir a hipótese que acabara de avançar referindo-se à circunstância de sermos, nas suas palavras, "meras réplicas de ADN dos nossos antepassados", é claro, por tudo o que nos é dado a experienciar no próprio filme, que este contaminação da esfera da vida pela esfera da arte, por meio da problematização do binómio cópia/original, conhece muitas outras declinações. Se não, vejamos: assim como a reprodução de um quadro é uma cópia do original, também a relação que Elle e James fingem (provavelmente) ter um com o outro será uma cópia das (prováveis) relações de ambos com os respectivos marido e mulher (de quem, no entanto, nada se sabe no filme); tal como os segundo, terceiro amores na vida de alguém se assemelharão a cópias de um primeiro amor, e - porventura - todos os dias ao longo de uma relação amorosa se poderão afigurar, também eles, cópias do primeiro dia - aquele que permanecerá inesquecível, o do encontro, o do acontecimento.

A questão da cópia - na arte e na vida - obriga, pois, a que se reflicta sobre fenómenos de desgaste (como o que afecta fotocópias de fotocópias de fotocópias), isto é, sobre a perda de nitidez, de brilho, de intensidade, e também, no plano da vida, sobre o declínio do entusiasmo pelo que acontece aqui e agora. Obriga a que se reflicta sobre isto; mas não apenas sobre isto; ou seja, obriga também - e sobretudo -, a que se reflicta contra isto. Trata-se de um desafio: como tornar único um dia perdido no meio de tantos outros dias numa relação amorosa com quinze anos? Ou: como restituir o brilho inicial do encontro amoroso? Como singularizar o dia de hoje, que, no entanto, é apenas mais um dia, como os outros, mera cópia. Assim, é como se o valor intrínseco da cópia - a cujo valor James dá tanta importância, pelo menos teoricamente - dependesse de ser ainda assim possível singularizá-la.

Creio que nos debatemos, por meandros em que o questionamento da arte e o da vida 
se confundem, com diferentes formas de lidar com a tese de que a cópia detém um valor intrínseco. Ora, para pesar a força desta tese, importa antes de mais afastar a sua interpretação mais imediata, corriqueira e tradicional - se não tradicionalista -, que consiste em julgar que o valor da cópia reside na sua capacidade de nos conduzir ao original e de assim manter viva a relação com a tradição (cujo carácter é simultaneamente visual, cultural, moral). Creio que esta interpretação, apesar de James se referir à relação com a tradição na sua apresentação do livro, não é, verdadeiramente, o espírito do seu trabalho, como o próprio subtítulo do livro ("Esqueça o original, arranje uma boa cópia") sugere, e vários episódios mais adiante no filme confirmam.

Com efeito, se levarmos a sério a tese de que a cópia detém um valor intrínseco, esse valor terá de ser de algum modo independente do original, e, porventura, independente da capacidade da cópia de restituir o original. Neste caso, a crer em Deleuze ${ }^{2}$, passaríamos do universo das imagens ao dos simulacros, universo em que a hierarquia entre a boa cópia (porque fiel ao original) e a má cópia (porque infiel ao original, traiçoeira, desviante) se desmorona. Esse valor intrínseco da cópia ameaça portanto a supremacia do original sobre a cópia e, no limite - como vimos a propósito da construção do filme em duas partes -, a possibilidade de distingui-los. Importa dar um exemplo que permita explicitar esta ideia: Elle parece ter efectivamente razão quando crê ter encontrado um exemplo paradigmático das teorias de James numa cópia (o retrato de uma jovem), que durante séculos se acreditou ser o original, cópia que ambos contemplam num museu em Lucignano, ao qual Elle faz questão de levar James; é que, como refere o guia do museu de forma um pouco ingénua mas reveladora, aquela cópia é talvez mais bela do que o original...

Para James, de facto, o valor daquela cópia não requer sequer a sua comparação com o original (o qual, à sua maneira, também é uma cópia). Daí o seu comentário irónico: "Afirmam adorar este quadro, mas [ressalvam] que é uma cópia e que o original está algures..." Para James, esta ressalva não faz, em última instância, sentido, motivo por que pergunta, pouco depois:

Que diferença faz? O original é apenas uma reprodução da beleza da rapariga retratada. Ela é que é o verdadeiro original. E, vistas as coisas deste prisma, mesmo a Mona Lisa é uma reprodução da Gioconda. E aquele sorriso... Será original ou foi Leonardo que lhe pediu que sorrisse assim?

Deste modo - nesta remissão de cópia para cópia, em que o original se revela cada vez mais fugidio -, se vê como esta espécie de subtracção do original, que poderá ser coextensivo à emancipação da cópia, alastra à relação entre ficção e realidade e, no plano da vida, ao contraste entre fingimento e autenticidade (contraste simbolizado pela questão de saber se o sorriso da Gioconda seria ou não "fingido").

A cópia e, com esta, a ficção e o fingimento, terão um valor intrínseco. Esta tese, no entanto, pode ser pesada, defendida, vivenciada de dois modos distintos - a 
contraposição destes dois modos constituiria o desentendimento encenado no filme, um desentendimento que, encarnando nas duas personagens principais, constitui um desentendimento em que se joga também - nesse vaivém entre a arte e a vida dentro do próprio filme e com consequências para nós - o estatuto da obra de arte, da experiência estética e ainda, porventura, da noção de aura.

Contra a preponderância do original, da seriedade, da autenticidade, James advoga a simplicidade da vida, o prazer, a espontaneidade, a superfície - ele afirma compreender e admirar a criança que não se preocupa com a possibilidade de ficar doente por estar a brincar à chuva. Mas esta é apenas uma das facetas - a mais óbvia - do personagem. Ao mesmo tempo, em contrapartida, é com pouco entusiasmo que James fica a conhecer a história da cópia (a tal alegadamente mais bela do que o original) exposta no pequeno museu em Lucignano, afirmando, de modo relativamente enfadado, depois de ouvir a explicação do guia, que sim, que é um exemplo interessante, mas que não constitui novidade... Do mesmo modo, é com cada vez mais fadiga, e parecendo cada vez mais impaciente e entediado, que lida emocionalmente com a tentativa de Elle de tornar aquele encontro único, com a tentativa, ao fim e ao cabo, de resgatar a "aura" daquele dia, independentemente de ser mais um dia na vida de um casal (cópia de todos os anteriores) ou um primeiro dia de um encontro (cópia de todos os anteriores primeiros dias de encontros passados).

O que quer dizer este cansaço, esta perda de entusiasmo? Que, perdido o original, tudo vai inevitavelmente dar ao mesmo? Que a indiferença, o alheamento, o tédio, a apatia o cinismo até -, levam por fim a melhor sobre o idealismo dos que crêem possível resgatar a aura do primeiro encontro após quinze anos? Que todas as imagens, mesmo as da arte, se tornaram banais? Curiosamente, é Elle quem resiste a este cenário desencorajante; e não James, que advoga teoricamente o valor intrínseco da cópia.

A pergunta que cabe formular - e na qual se jogam duas interpretação da emancipação da cópia, que mais não é do que o advento de um mundo de simulacros - é então a seguinte: será que a cópia se emancipa - na medida em que o seu valor não será inferior ao de um original - para que todas as imagens, todos os simulacros, se tornem indiferentemente semelhantes, igualmente baços, identicamente banais; ou, muito pelo contrário, para que o brilho da cópia se possa tornar fulgurante, para que cada dia se possa tornar único, para que valha a pena a ficção, e ao fingimento se reconheça o poder de desmascarar tantas mentiras (e não é através do fingimento, de uma ficção, que ambos arriscam... um novo encontro?), ou ainda, para que, por fim, subsista aqui e agora o espanto diante do que até pode ser uma cópia; ou seja, porventura, para que uma "certa aura" resista ao seu anunciado declínio?

Voltemos atrás no tempo. Para Benjamin, o declínio da aura significava, de um modo positivo, a crítica da tradição cultural e apontava na direcção da possibilidade da sua apropriação por qualquer um: a distância consignada pela aura - pois é em termos 
metafórica e literalmente espaciais que Benjamin define a aura, enquanto "aparecimento único de algo distante, por mais perto que esteja" ${ }^{3}$ - era, para Benjamin, inimiga da "aspiração apaixonada das massas do presente", que consistiria precisamente em "'trazer' as coisas, espacial e humanamente, para perto de si". ${ }^{4}$

Ora, é precisamente para aproximar espacial e humanamente do seu filho - no fundo, do olhar espantado de qualquer criança -, as figuras escultóricas da Piazza della Signoria que a personagem interpretada por Juliette Binoche mantém a ilusão de que estariam ambos, mãe e filho, lado a lado, diante de originais. É a experiência de um olhar em que a curiosidade, o susto e a admiração se misturam que a mãe quer salvaguardar. Pois o espanto, para a criança, não é nada mais nada menos do que aquilo que precisamente pode aproximá-la disso que pode revelar-se espantoso. Só assim uma tal experiência fará parte da memória daquela criança; só assim ela fará daquele olhar uma experiência sua; só assim, pois, se concretiza a tal apropriação, que a referida proximidade - uma proximidade paradoxal porque inseparável da distância característica de tudo o que não é imediatamente compreensível - torna possível.

A situação é efectivamente paradoxal, pois a aproximação espacial e humana em relação ao objecto artístico - que Benjamin considerava decorrente do declínio histórico da aura - parece aqui associada aos caracteres definidores da experiência aurática: a experiência aqui e agora de algo distante que espanta por escapar a uma compreensão imediata... Mais: uma tal aproximação espacial e humana, contra a banalização e o empobrecimento generalizados da experiência, parece ter como condição esses caracteres. Para que isto se torne inteligível, contudo, é necessário libertar a noção de "aura" do binómio constituído pelas noções de "original" e de "cópia" (no contexto da qual se é levado a associá-la exclusivamente ao "original"), o que implica, ao mesmo tempo, desvinculá-la da esfera da religião (perspectiva também defendida por Georges DidiHuberman, ainda que num contexto distinto ${ }^{5}$.

Ora, é isto precisamente que parece ganhar corpo em Cópia fiel: Elle parece lutar inconscientemente por que a aura - e o espanto de que ela releva - sobreviva ao colapso da hierarquia entre cópia e original, sobrevivência em que a aura não só se revela manifestamente irredutível à sua definição religiosa, como inunda a esfera de uma experiência inteiramente secularizada; tal acontece em Cópia fiel pois é precisamente através de uma ficção (da tal ficção dentro da ficção), logo, de uma cópia (de uma cópia como que emancipada do original) que se procura resgatar a aura, a singularidade ainda que copiada -, do encontro amoroso, e, com ele, a singularidade de tudo o que se repete, tanto na arte como na vida.

Resgatar a aura - numa era em que proliferam imagens há muito desvinculadas de um original, numa era em que o declínio da aura se transformou num slogan - mais não é do que uma forma de combater o empobrecimento da experiência que consiste em ver uma imagem artística, em confrontar-se com uma obra de arte, em espantar-se aqui e agora 
com o que até pode ser uma mera cópia. É a singularidade de uma tal experiência que está em causa, e a possibilidade da sua apropriação por qualquer um, mesmo no caso de uma cópia. É, pois, a hipótese de uma aura da cópia, do simulacro, da imagem artística que está também em causa.

Por fim, poderíamos questionar-nos sobre se a reaç̧ão da criança, na Piazza della Signoria, teria sido diferente se soubesse que se tratava de uma cópia, e não de um original. Mas essa é uma pergunta para a qual não é possível obter uma resposta. Decisivo, porém - diria eu, para terminar -, não é tanto saber quão determinante para a experiência da criança foi o facto de acreditar estar perante um original, mas saber em que acreditamos nós diante de uma imagem, diante de uma obra de arte (independentemente de se tratar de um original, de uma cópia manual ou de uma reprodução técnica), diante de uma ficção como a que se nos apresenta em Cópia Fiel; saber, pois, se acreditamos, e até que ponto acreditamos, no seu poder interrogador, e que consequências estamos dispostos a tirar desse poder, expondo-nos a ele, imaginando-o - e tornando-o - nosso.

\section{* João Pedro Cachopo é pós-doutorando pela Universidade Nova de Lisboa.}

1 Uma primeira versão deste breve ensaio foi apresentado no colóquio "Imagem, Imaginação e Fantasia. Vinte anos sem Vilém Flusser" que teve lugar em Ouro Preto em Outubro de 2011. Gostaria de deixar uma nota de agradecimento aos seus organizadores, em particular aos Professores Rodrigo Duarte e Romero Freitas, pelo seu caloroso acolhimento, bem como à Cíntia Vieira da Silva e ao Patrick Pessoa, que, com outros colegas e amigos, participaram na discussão que se seguiu à comunicação, contribuindo de modo decisivo para o prolongamento das linhas de pensamento que se cristalizaram, entretanto, na actual versão do texto.

${ }^{2}$ DELEUZE, G. Logique du sens. Paris: Minuit, 1969, pp. 292-306.

3 BENJAMIN, W. "Das Kunstwerk im Zeitalter seiner technischen Reproduzierbarkeit". In: Gesammelte Schriften, I.2. Frankfurt am Main: Surhkamp, 1974, p. 479.

${ }^{4}$ Ibidem.

${ }^{5}$ Com efeito, a secularização do conceito de "aura" foi preconizada por Georges Didi-Huberman sobretudo em O que nós vemos, o que nos olha [Ce qui nous voyons, ce qui nous regarde, 1992], mas também em Perante o tempo [Devant le temps, 2000] -, e isto no quadro de uma reflexão sobre arte contemporânea em que a noção de "aura" não teria perdido, ao contrário do que tantas vezes se dá por adquirido, a sua pertinência. Porém, diferentemente do que no presente texto se ensaia - sem prejuízo da afinidade que possa existir entre duas formas de resgatar o conceito -, o fio condutor da reflexão sobre a aura encetada por Didi-Huberman não diz tanto respeito a uma problematização da hierarquia entre cópia e original, quanto à tentativa de pensar dialecticamente o poder da distância que está em jogo de cada vez que se olha para - e se é olhado por - uma imagem/objecto artísticos (tratando-se, à partida, de originais...). Trata-se, recorrendo à noção de 
"aura", de escapar às lógicas alternativas da crença e da tautologia: a aura permitiria pensar o que em determinadas obras de arte é mais do que é imediatamente visível, sem, contudo, associar essa "invisibilidade" a uma qualquer transcendência de carácter religioso; a aura permitiria pensar o excesso imanente à própria arte. Daí que, no que toca a este conceito, o cerne da argumentação de Didi-Huberman consista em apresentar o "valor de culto" como uma entre outras possíveis declinações históricas da aura (nunca como a única possível), cumprindo assim reler o conceito avançado por Benjamin, ressalvar a sua irredutibilidade à esfera da religião e, finalmente, realçar a sua valência crítica para pensar objectos de arte contemporânea, mesmo os mais insuspeitos de possuírem características susceptíveis de serem associadas à noção de "aura", como certas obras de arte minimalistas, de Tony Smith ou Robert Morris, por exemplo. 